\title{
Construction of Piston Outer Profile for Rotary Type Expansion Machine
}

\author{
Yury Zhuravlev \\ Department of Road Construction \\ Pskov State University \\ Pskov, Russia \\ drakon426@mail.ru \\ Sergey Tikhonov \\ Department of Mechanics and Motor \\ Trantsport Service \\ Pskov State University \\ Pskov, Russia \\ sit42@rambler.ru
}

\author{
Andrey Perminov \\ Department of Electric Drive and Auto- \\ mation Systems \\ Pskov State University \\ Pskov, Russia \\ alp-mail@mail.ru \\ Alexander Ilyin \\ Department of Electric Drive and Auto- \\ mation Systems \\ Pskov State University \\ Pskov, Russia \\ al.ilyin@yandex.ru
}

\author{
Yury Lukyanov \\ Department of Electric Drive and Auto- \\ mation Systems \\ Pskov State University \\ Pskov, Russia \\ luk-yra@mail.ru
}

\begin{abstract}
The article discusses methods for constructing piston outer profile for the rotary type expansion machine in order to reduce unwanted (parasitic) volumes and offers options for constructing outer profile of piston using analytical and geometric methods.
\end{abstract}

Keywords-lever-cam motion converter, power generation system, rotary engine.

\section{INTRODUCTION}

The subject of this article is the rotary expansion machine (patent RU2619391) published by the authors in 2017 [1].

The machine contains four pistons, forming an equilateral four-link mechanism in the form of a mobile rhomboid. The ends of pistons are in full sliding contact with inner surface of chamber, the profile of which is the external equidistant, spaced by a distance of radius $R_{l}$ of ends of piston from reference curve, described in polar coordinates $\rho$ and $\alpha$ with equation

$$
\rho(\alpha)=L \sin [a+b \cos 2 \alpha],
$$

where $\mathrm{L}$ is the distance between the axes of the piston hinges; $a=\pi / 4 ; b=\pi / 4-\psi_{\min } 2$, and where $\psi_{\min }$ is the minimum angle between the pistons.

The optimal value of this angle is $\psi_{\text {опт }}=1.221 \mathrm{rad}$, at which $\mathrm{a}=0.7854 \mathrm{rad}, \mathrm{b}=0.1749 \mathrm{rad}$. The outer surface of each piston has the shape of an arc of a circle of radius $R$, the value of which is chosen in such a way that in the position $\alpha=\pi / 4=45^{\circ}$, in which the four-link mechanism is square, the surface of piston touches internal cavity of chamber at three points. Therefore, in this position, two working volumes are formed, isolated from the rest of chamber space.

The task is to determine outer surface of the piston, in which in the position $\alpha=\pi / 4$, the working volumes will be absent, i.e. piston profile will coincide completely with inner surface of chamber, which is equidistant.

\section{FIRST OPTION}

The initial position of piston $\mathrm{AB}$ with $\alpha=\pi / 4$ is shown in Fig. 1.

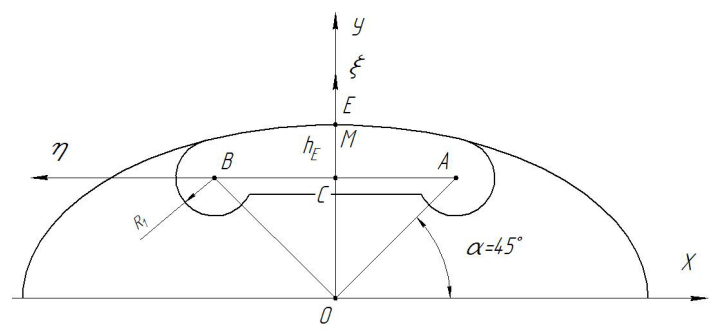

Fig. 1. Initial position of piston

Point $\mathrm{E}$ belongs to equidistant, and point $\mathrm{M}$ coinciding with it belongs to piston. We introduce a fixed coordinate system $\mathrm{xOy}$ with the beginning at the point $\mathrm{O}$ of the worker in the center of the cylinder. We introduce the following notation: $A B=L, O C=L / 2, y E=L \sin (a+b)+R_{1}$. When $a=0,7854, b=0.1749$, we get $y E=0.573 L+R_{1}$. Then the segment $C E=h_{E}=y_{E}-0.5 L$, or $h_{E}=0.079 L+R_{l}$.

Fasten with the piston the moving coordinate system $C \xi \eta$ with the origin at point $C$ (Fig. 2).

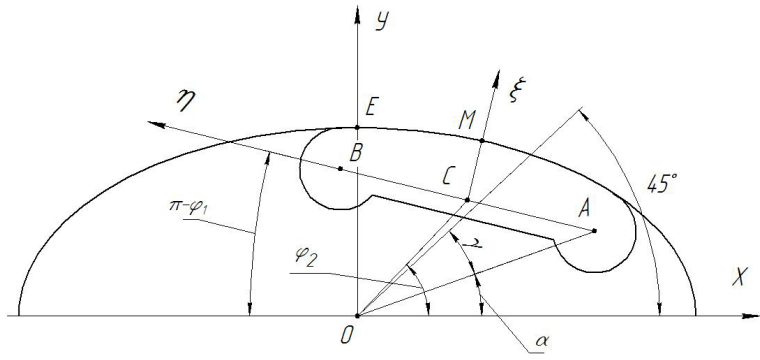

Fig. 2. Arbitrary position of piston

In moving axes, point $\mathrm{M}$ will have coordinates $\xi_{M}=h_{E}, \eta_{M}=0$. Determine the trajectory of point $M$ when the piston moves from the position $\alpha=\pi / 4$. That the angle Print ISSN 1691-5402

Online ISSN 2256-070X

http://dx.doi.org/10.17770/etr2019vol3.4059

(C) 2019 Yury Zhuravlev, Andrey Perminov, Yury Lukyanov, Sergey Tikhonov, Alexander Ilyin. Published by Rezekne Academy of Technologies. This is an open access article under the Creative Commons Attribution 4.0 International License. 
$\alpha$ decreases by the value determined by the angle $\gamma$, i.e. $\alpha$ $=\pi / 4-\gamma$. Then the coordinates of the point $M$ are defined as

$$
\left\{\begin{array}{c}
x_{M}=x_{C}+\xi_{M} \cos (\hat{x, \xi})+\eta_{M} \cos (\hat{x, \eta})= \\
\frac{L}{2} \cos \varphi_{2}+h_{E} \sin \varphi_{1} \\
y_{M}=y_{C}+\xi_{M} \cos (\hat{y, \xi})+\eta_{M} \cos (\hat{y, \eta})= \\
\frac{L}{2} \sin \varphi_{2}-h_{E} \cos \varphi_{1}
\end{array}\right.
$$

where $\varphi_{-} 1$ is the angle between axes $\eta \mathrm{x} ; \varphi_{2}$ is the angle between axes $\xi \mathrm{x}$.

Express the angles $\varphi_{1}$ and $\varphi_{2}$ through the angle $\gamma$ :

$$
\begin{aligned}
& \varphi_{1}=\pi-\gamma+b \sin 2 \gamma ; \\
& \varphi_{2}=\pi / 2-\gamma-b \sin 2 \gamma .
\end{aligned}
$$

Then the trajectory of the point $\mathrm{M}$ in a parametric form is $x_{M}=x_{M}(\gamma), y_{M}=y_{M}(\gamma)$.

For known coordinates of the point $M X_{M}$ and $Y_{M}$ in a fixed coordinate system, we find the coordinates $\xi_{M} \eta_{M}$ in the moving coordinate system. Using equation (2) we get

$$
\left\{\begin{array}{l}
\eta_{M} \cos \varphi_{1}+\xi_{M} \sin \varphi_{1}=x_{M}-x_{C} \\
\eta_{M} \sin \varphi_{1}-\xi_{M} \cos \varphi_{1}=y_{M}-y_{C}
\end{array}\right.
$$

Solving the system of equations (4) with respect to $\xi_{M} \eta_{M}$ and taking into account that $x_{C}=L / 2 \cos \varphi_{2}, y_{C}=L / 2 \sin \varphi_{2}$, $\varphi_{1}-\varphi_{2}=\pi / 22 b \sin 2 \gamma$ we get.

$$
\left\{\begin{array}{rrr}
+y_{M} \cos (\gamma & b \sin 2 \gamma) & \frac{L}{2} \cos (2 b \sin 2 \gamma) \\
\eta_{M}= & x_{M} \cos (\gamma \quad b \sin 2 \gamma)+ \\
+y_{M} \sin (\gamma & b \sin 2 \gamma)+\frac{L}{2} \sin (2 b \sin 2 \gamma)
\end{array}\right.
$$

The solution of this system of equations has a parametric form: $\xi_{M}=\xi_{M}(\gamma), \quad \eta_{M}=\eta_{M}(\gamma)$

In the position $\alpha=\pi / 4-\gamma$ the point $M$ of the piston must coincide with the point $E$ of the equidistants having the coordinates $x_{E}=x_{M}=0, y_{E}=y_{M}=0.573 L+R_{I}$.

Then, by expression (5) the point $M$ must have coordinates

$$
\left\{\begin{array}{ll}
\xi_{M}=y_{E} \cos (\gamma \quad b \sin 2 \gamma) \quad \frac{L}{2} \cos (2 b \sin 2 \gamma) \\
\eta_{M}=y_{E} \sin (\gamma \quad b \sin 2 \gamma)+\frac{L}{2} \sin (2 b \sin 2 \gamma)
\end{array} .\right.
$$

The system of equations (6) gives the coordinate values $\xi_{M}=\xi_{M}(\gamma), \eta_{M}=\eta_{M}(\gamma)$ with decreasing angle $\alpha$, i.e. when $\alpha=\pi /(4-\gamma)$, where it is considered $\gamma>0$.

In the case of increasing $\alpha$, i.e. when $\alpha=\pi(4+\gamma)$, in the formula (6) it is necessary to change the sign of $\gamma$ to the opposite taking $\gamma<0$. Given the parity of trigonometric functions, the equation for $\xi_{M}$ remains unchanged and in the equation for $\eta_{M}$ both terms will change sign. Therefore, equation (6) is valid in the range of the angle $-\gamma_{\max } \leq \gamma \leq \gamma_{\max }$, where the value of $\gamma_{\max }$ should correspond to the contact of the obtained curve with the circle of the end curve of the piston of radius $R_{l}$. Obviously, this tangency is possible when $\gamma_{\max }=\pi / 4$.
Computer simulation made in SolidWorks has shown that if the piston profile is given exactly the profile of the equidistant chamber in the position $\alpha=45^{\circ}$. This will jam when moving from this position. Obviously, the profile synthesis problem is multivariate.Second option

Fig. 3 shows the piston in an arbitrary position.

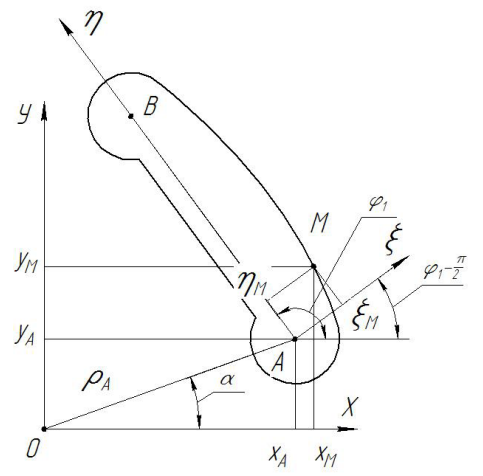

Fig. 3. Arbitrary position of piston

The current position of the piston $A B$ in the fixed coordinate system $O x y$ is determined by the coordinates $x_{A}$ and $y_{A}$ of the hinge $A$, as well as by the angle $\varphi_{1}$ of the inclination of the axis of the piston $A B$ to the axis $O x$.

Where: $\mathrm{x}_{\mathrm{A}}=\rho_{\mathrm{A}} \cos \alpha, \mathrm{y}_{\mathrm{A}}=\rho_{\mathrm{A}} \cos \alpha, \rho_{\mathrm{A}}=\rho(\alpha)=\mathrm{L} \sin (\mathrm{a}+\mathrm{b}$ $\cos 2 \alpha), \varphi 1=\frac{3 \pi}{4} \cos 2 \alpha$.

Let us introduce the moving coordinate system $\xi \eta$ fixed to the piston with the beginning at point $A$. We choose an arbitrary point $M$ on the piston profile, which has coordinates $\xi_{M}$ and $\eta_{M}$ in the moving coordinate system $\mathrm{A} \xi \eta$. The coordinates of this point in the fixed coordinate system $O x y$ are determined by the coordinate transformation formulas:

$$
\left\{\begin{array}{l}
x_{M}=x_{A}+\xi_{M} \cos (\widehat{x, \xi})+\eta_{M} \cos (\widehat{x, \eta}) \\
y_{M}=y_{A}+\xi_{M} \cos (\widehat{y, \xi})+\eta_{M} \cos (\widehat{y, \eta})
\end{array}\right.
$$

or

$$
\left\{\begin{array}{l}
x_{M}=x_{A}+\xi_{M} \sin \varphi_{1}+\eta_{M} \cos \varphi_{1} \\
y_{M}=y_{A} \quad \xi_{M} \cos \varphi_{1}+\eta_{M} \sin \varphi_{1}
\end{array}\right.
$$

Consider the same piston in the position $\alpha=45^{\circ}$ (Fig. 4)

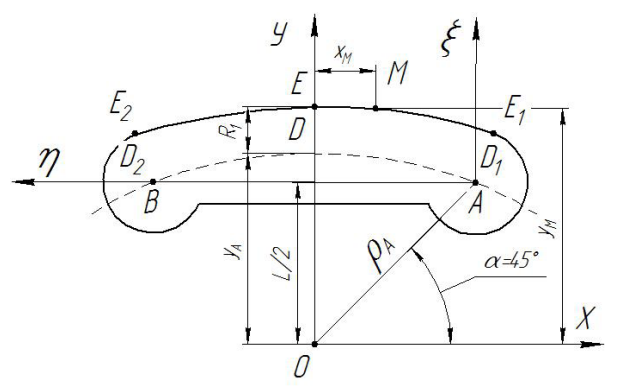

Fig. 4. Position of the piston at $\alpha=45^{\circ}$

In this position, the three points of the piston profile $D$, $D 1, D 2$ touch the equidistants of the chamber at points $E$, $E 1, E 2$. The highest point of the piston profile $D$ has the following coordinates

$$
\begin{gathered}
x_{D}=x_{E}=0 \\
y_{D}=y_{E}=\rho\left(\frac{\pi}{2}\right)+R_{1}=L \sin \left(\begin{array}{ll}
a & b
\end{array}\right)+R_{1} .
\end{gathered}
$$


When the piston moves from the position to the position $\alpha=45^{\circ}+\Delta \alpha$, the points $D_{1}, E_{1}$ and $D_{2}, E_{2}$ change their position, but the contact between them remains. The upper point of the piston $\mathrm{D}$ will also leave the point of the chamber $E$. We will find such a profile of the piston, at which the contact of the points of the profile $M$ and the point $\mathrm{E}$ of the chamber will remain in a certain range of the increment of the angle $\Delta \alpha$. This means that it is necessary to determine the coordinates $\xi_{M}$ and $\eta_{M}$ of the point $\mathrm{M}$ so that in the position $\alpha=45^{\circ}+\Delta \alpha$, the coordinates of this point $x_{M}$ and $y_{M}$ are equal to the coordinates $x_{E}$ and $y_{E}$ of point $E$.

$$
\begin{gathered}
x_{M}\left(45^{\circ}+\alpha\right)=x_{E}, \\
y_{M}\left(45^{\circ}+\alpha\right)=y_{E}=L \sin \left(\begin{array}{ll}
a & b
\end{array}\right)+R_{1} .
\end{gathered}
$$

As a result, we arrive at the following system of equations for $\xi_{M}$ and $\eta_{M}$

$$
\left\{\begin{array}{c}
\xi_{M} \sin \varphi_{1}(\beta)+\eta_{M} \cos \varphi_{1}(\beta)=x_{A}(\beta) \\
\xi_{M} \cos \varphi_{1}(\beta)+\eta_{M} \sin \varphi_{1}(\beta)= \\
y_{A}(\beta)+L \sin (a \quad b)+R_{1}
\end{array},\right.
$$

where $\beta=45^{\circ}+\alpha, \quad x_{A}(\beta)=\rho_{A}(\beta) \cos \beta$, $y_{A}(\beta)=\rho_{A}(\beta) \sin \beta, \quad \rho_{A}(\beta)=L \sin (a+b \cos 2 \beta)$, $\varphi_{1}(\beta)=\beta+\frac{3 \pi}{4}+b \sin 2 \beta$.

Solving system (10) according to Kramer's rule $\xi_{M}=$ $\xi /, \eta_{M}=\eta /$ we get:

$$
\begin{aligned}
& =\left|\begin{array}{cc}
\sin \varphi_{1}(\beta) & \cos \varphi_{1}(\beta) \\
\cos \varphi_{1}(\beta) & \sin \varphi_{1}(\beta)
\end{array}\right|=1,
\end{aligned}
$$

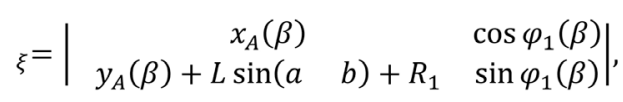

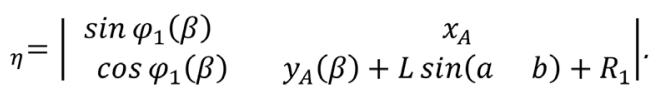

Then

$$
\begin{gathered}
\xi_{M}=x_{A}(\beta) \sin \varphi_{1}(\beta) \\
{\left[\begin{array}{cc}
y_{A}(\beta)+L \sin (a & b)+R_{1}
\end{array}\right] \cos \varphi_{1}(\beta)} \\
\eta_{M}=x_{A}(\beta) \cos \varphi_{1}(\beta)+ \\
{\left[\begin{array}{cc}
y_{A}(\beta)+L \sin (a & \left.b)+R_{1}\right] \sin \varphi_{1}(\beta)
\end{array}\right.}
\end{gathered}
$$

Varying the value of the increment of the angle $\alpha$ in the range $0 \leq \alpha \leq 45^{\circ}$, or the same as the angle $\beta=$ $45^{\circ}+\alpha$ in the range $45^{\circ} \leq \alpha \leq 90^{\circ}$, from equation (12) we obtain the desired piston profile.

In the process of movement each point $M\left(\xi_{M}, \eta_{M}\right)$ of the synthesized piston profile will move along its own trajectory of the form $x_{M}=x_{M}(\alpha)$ and $y_{M}=$ $y_{M}(\alpha)$, defined by equation (7). It is important to check the absence of the intersection of these trajectories with the equidistant curve defined by the equations $x_{E}=$ $x_{E}(\alpha)$ and $y_{E}=y_{E}(\alpha)$. Otherwise, the piston will jam in the housing.
If there is an intersection of the trajectories with equidistant, the wording of the problem should be changed. We require that in the position $\alpha=45^{\circ}+$ $\alpha$, the coordinates $x_{M}$ and $y_{M}$ of the point $M$ should be equal to the coordinates of $x_{E^{\prime}}$ and $y_{E^{\prime}}$ of point $E^{\prime}$ (Fig. 5, a) located on the axis Oy below point $E$ at some distance $=(\alpha)$. Then we have

$$
\begin{aligned}
& x_{M}\left(45^{\circ}+\alpha\right)=x_{E^{\prime}}, \\
& y_{M}\left(45^{0}+\alpha\right)=y_{E^{\prime}}=y_{E} \quad(\alpha)= \\
& L \sin \left(\begin{array}{ll}
a & b
\end{array}\right)+R_{1} \quad(\alpha) \text {. }
\end{aligned}
$$

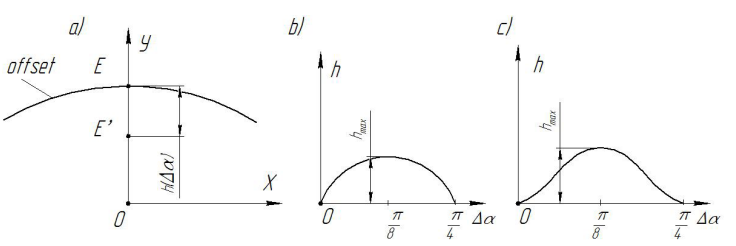

Fig. 5. Types of functions

In this case equation (12) is somewhat modified and takes the form

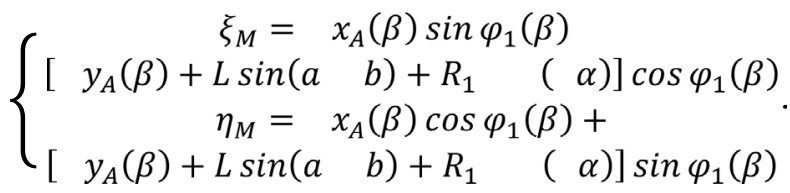

The type of the function $h(\Delta \alpha)$, which varies in the range $0 \leq \Delta \alpha \leq 45^{\circ}$, should be specified. It is known that this function should be equal to zero at two extreme points $\Delta \alpha=0$ and $\Delta \alpha=45^{\circ}$. It can be offered two types of this function:

sinusoidal (Fig. 5, b): $\quad(\alpha)=\max _{\min } \sin (\alpha)$ cosine (Fig. 5, c): $\quad(\alpha)=\frac{h_{\max }}{2}(1 \quad \cos 8(\alpha))$.

In both cases it is possible by varying the value of $h_{\max }$ to achieve the absence of jamming of the piston in the housing. The decision on which option is preferable can be made based on the results of calculations.

\section{REFERENCES}

[1] RF Patent 2619391 for an invention. Int. Cl. F01C1/44. Rotary Expantion Machine / Y.N. Lukyanov, Y.N. Zhuravlev et al. Publ. 15.05.2017.

[2] Y.Zhuravlev, A.Perminov, Y.Lukyanov, S.Tikhonov, A.Ilyin, S.Semyonov, Optimization of Mechanical Strength of Rotary-Vane Engine. "Environment. Technology. Resources - Proceedings of the 11th International Scientific and Practical Conference", 2017.

[3] S.Semyonov, S.Tikhonov, Y.Lukyanov, A.Perminov, Analysis Method of Calculation Parameters of Heat and Mass Transfer Processes in the Stirling Engine. "Environment. Technology. Resources - Proceedings of the 11th International Scientific and Practical Conference", 2017.

[4] Y.Zhuravlev, A.Perminov, Y.Lukyanov, S.Tikhonov, A.Ilyin, et al. Calculation and design of a rotary vane machine with external heat supply. Monograph. Pskov, 2012.

[5] Y.Zhuravlev, A.Perminov, Y.Lukyanov, S.Tikhonov, A.Ilyin, et al. Mathematical models of physical processes in a rotary-blade engine with external heat supply. Monograph. Pskov, 2012.

[6] Zhuravlev Y.N., Perminov A.L., Luk'yanov Y.N., Tikhonov S.I., Semonov S.N. Minimizatsiya mekhanicheskoy napryazhennosti rotorno-lopastnogo teplovogo dvigatelya s rychazhno-kulachkovym preobrazovatelem dvizheniya. Vestnik Pskovskogo gosudarstvennogo universiteta. Seriya: Tekhnicheskiye nauki. 2016. № 4.

[7] RF Patent 2374526 for an invention. Int. Cl. F16H25/04. Mechanism for converting motion / Y.N. Lukyanov, Y.N. Zhuravlev et al. 
Publ. 27.11.2009. Bull. Number 33.

[8] RF Patent 2387844 for an invention. Int. Cl. F01G1/077, F02G1/044. Rotary-vane engine with an external supply of heat .N. Lukyanov, Y.N. Zhuravlev et al. Publ. 27.04.2010. Bull. Number 12 .

[9] Perminov A., Lukyanov Y., Tikhonov S., Ilyin A. Thermodynamic cycle with two-component working fluid. "Environment Technology. Resources - Proceedings of the 11th International Scientific and Practical Conference", 2015. DOI: 10.17770/etr$2015 \mathrm{vol} 2.261$

[10] Perminov A. L., Khitrov A. A., Khitrov A. I. Mekhatronnaya sistema "magnito-elektricheskiy sinkhronnyy dvigatel' - aktivnyy vypryamitel'» dlya avtonomnoy sistemy elektrosnabzheniya na baze rotorno-lopastnoy mashiny s vneshnim podvodom tepla.
Trudy VII Mezhdunarodnoy (VIII Vserossiyskoy) konferentsii po avtomatizirovannomu elektroprivodu AEP-2012: "Ivanovskiy gosudarstvennyy energeticheskiy universitet". - Ivanovo, 2012. 708 p. pp. 330-335.

[11] Perminov A.L., Luk'yanov YU.N., Tikhonov S.I., Il'in A.V. Elektrogeneratory dlya energoustanovok. Elektromekhanika. Elektroenergetika. Informatsionnyye tekhnologii Sbornik materialov 1-go Mezhdunarodnogo nauchno-prakticheskogo seminara. 2018. pp. 52-55. 